\title{
Carbon sequestration in tropical Asia: an assessment of technically suitable forest lands using geographic information systems analysis
}

\author{
Louis R. Iverson ${ }^{1,2}$, Sandra Brown ${ }^{3}$, Alan Grainger ${ }^{4}$, Anantha Prasad ${ }^{2,3}$, Dawning Liu ${ }^{2,3}$ \\ 1 U.S. Forest Service, 359 Main Rd, Delaware, Ohio 43015, USA \\ ${ }^{2}$ Illinois Natural History Survey, 607 E. Peabody Dr., Champaign, Illinois 61820, USA \\ ${ }^{3}$ Department of Forestry, University of Illinois, W-503 Turner Hall, 1102 S. Goodwin, Urbana, Illinois 61801, USA \\ ${ }^{4}$ School of Geography, University of Leeds, Leeds LS2 9JT, England
}

\begin{abstract}
Tropical forest lands hold the greatest promise for sequestering large quantities of carbon. In thus study, an analysis was performed to produce a first order map of the technical suitability of present-day forest lands to sequester additional carbon in the continental part of tropical Asia. The analysis used a geographic information system (GIS) approach to assess the difference between 2 indices of potential and actual carbon sequestration of forests on a regional scale. This difference represents the degree to which forest biomass has been reduced (degraded) from its potential maximum caused by the long history of human impacts on the landscape. The difference indicates the relative amount of new biomass carbon which could be added to particular areas of land if they were protected, free from human disturbance, so that they could accumulate biomass up to their potential with no social, economic, or political constraints. A potential carbon sequestration index (PCSI) map was derived from a GIS model based un cimatic and geomorphological factors. The actual carbon sequestration index map was derived via 2 methods: a degradation approach based on population densities ard climate zones, and a remote sensing approach based on a 4 yr mean of the normalized difference global vegetation index derived from NOAA AVHRR satellite imagery. Despite limitations, the methods provided reasonable maps of regional technical suitability on which to build as data quality and methodologies improve. Areas of highest technical suitability included the lowland moist and lowland seasonal ecofloristic zones, closed forests, and Peninsular Malaysia and India. On average, the technically suitable present forest lands could sequester an additional ca $90 \mathrm{Mg} \mathrm{C}^{-1}$ in aboveground biomass.
\end{abstract}

\section{INTRODUCTION}

The continued rise in atmospheric $\mathrm{CO}_{2}$ concentration and its probable effect on global climate through the greenhouse effect make it necessary to explore all possible mitigation strategies. One possibility is to cut the rate of emissions, by curtailing either fossil fuel combustion or tropical deforestation - the 2 main sources of anthropogenic $\mathrm{CO}_{2}$ emissions. Another is to enhance the natural carbon sequestration capabilities of vegetation on lands whose vegetation is currently degraded or otherwise underproductive, but large areas of land will be needed for this to have any significant mitigating impact. Because the tropics contain a large area of degraded land (Grainger 1988), they seem to provide the most appropriate focus for international action. However, previous estimates of the potential area of land which could be used in this way have suffered from poor data and an inability to distinguish spatially between lands with differing contributions to make to climate change mitigation. It has also been often assumed, wrongly, that lands which are technically suitable for carbon enhancement are actually available for this purpose.

This paper reports the initial results of a research project which is developing new techniques for determining the area of present forest lands which could sequester more carbon. The technical suitability of forest lands for carbon enhancement is assessed by ranking them (from high to low) according to their 
deviation from their maximum carbon density. It involves comparing the potential for forests to store carbon, estimated in the form of an index based on climate, soil type, and topography, with an actual biomass density index, based on population density and climate or on low resolution Advanced Very High Resolution Radiometer (AVHRR) satellite data. The difference between the potential and actual biomass density indices forms the basis of our evaluation of technical suitability. This procedure is applied to the tropical Asian region with geographic information system (GIS) modelling using numerous global/ regional databases. Results are given for 2 spatially explicit estimates of technical suitability, and discussed in terms of geographic specificity, ecofloristic zones, and vegetation types. We conclude with a discussion on the need for further refinements required to better estimate and locate the areas of technically suitable present forest lands, and the need to adjust these areas to take account of the actual availability of land for carbon enhancement.

\section{ASSESSING THE POTENTIAL FOR CARBON ENHANCEMENT}

\section{The carbon store and sink approaches}

The potential for increasing biotic carbon sequestration can be assessed in 2 main ways: the carbon store approach and the carbon sink approach.

The carbon store approach. This approach focuses on merely increasing the total amount of carbon stored in the terrestrial biota relative to that in the atmosphere. Lands with a degraded vegetation cover, and hence a lower carbon biomass density (the mass of carbon per unit area) than the maximum potential value for that site and type of vegetation, are identified as having potential for restoration. Existing degraded (secondary) forests, for example, could, with proper protection, sequester more carbon by natural or artificial regeneration. The mean net herbaceous biomass on cropland could also be increased by greater productivity (though if this requires fertilizers and pesticides produced from fossil fuels, it could be of limited net value from a carbon perspective). Alternatively, the tree cover on cropland or pastures could be increased, or new forests and plantations established on deforested lands. The carbon store approach is convenient for large-area surveys like the one described in this paper, but treats forests only as a stock resource rather than a renewable resource. The disadvantage is that increasing the carbon biomass density of an existing forest to make it as close as possible to the potential value only produces a net carbon sequestration over a limited period, which is less helpful in the longer term given the fact that the need to offset anthropogenic carbon dioxide emissions is expected to continue indefinitely. Little attention is paid to growth rates or wood harvesting in this approach.

The carbon sink approach. The carbon sink approach, on the other hand, recognizes that forests are renewable resources and focuses on increasing the annual rate of biotic carbon sequestration. Whether this approach involves increasing the growth rates of existing forests or establishing new forests or plantations, the overall aim is for the annual sequestration rate to account for a growing proportion of the annual rate of carbon dioxide emissions or the net annual rate of increase in atmospheric $\mathrm{CO}_{2}$ content (Sedjo \& Solomon 1989, Grainger 1990a). The carbon sink approach is probably more attractive to policy makers because it can be equated directly with these emissions, and with efforts to reduce them, e.g. through taxes on fossil fuel use or subsidies for energy conservation. It also puts an emphasis on wood harvesting because this allows the forest to continue sequestering carbon indefinitely in successive rotations. Two types of sinks may be distinguished, essentially by what happens to the wood after harvesting:

The ongoing sink: This type consists of forests or forest plantations with medium to long rotations. The wood is harvested when trees reach maturity and is converted into sawnwood, plywood, or other industrial wood products that enable sequestered carbon to be stored for a long period. How long is uncertain, although Kurz et al. (1992), for example, estimated a mean retention time for construction lumber in Canada of $65 \mathrm{yr}$.

The limited sink: This type consists of forests or forest plantations dedicated to fuelwood production, typically on shorter rotations. Their role as sinks is generally limited to the first rotation. At the end of this rotation, the wood is burned and thereafter the forest only adds to the global biotic carbon store (over the long term) a net amount equivalent to the mean mass of carbon stored within it during the course of a single rotation (Schroeder 1992). So the long-term capacity to reduce the present atmospheric $\mathrm{CO}_{2}$ content is limited, but because the fuelwood substitutes for fossil fuels, such plantations can reduce the rate at which the $\mathrm{CO}_{2}$ content rises in the future. The extent to which a sink is limited or ongoing depends on the retention times for harvested wood, and in practice on the proportion of wood burned as fuel.

The store and sink approaches are obviously complementary. Programs to expand the carbon sink will often, but not always, increase the biotic carbon store, but their main focus is to sequester carbon to counter continuing anthropogenic emissions. Programs to ex- 
pand the biotic carbon store may increase the carbon sink, but this is not a priority. Neither is harvesting the wood. Indeed, forests classified as requiring treatment to increase their carbon stores because their biomass densities are inferior to their potential values could actually be regenerating naturally towards these limits and are currently valuable carbon sinks. However, comparing actual and potential carbon stores does have the advantage that it can identify not only lands with potential for increasing the present stores but also, with discrimination, lands whose biomass is so degraded that they could form the site for new forests and plantations capable of increasing the carbon sink. In this paper, we assess the potential for increasing the carbon store on forest lands in continental South and Southeast Asia, but are careful to evaluate the limitations of our results with reference to the carbon sink approach.

\section{Lands needed for carbon sequestration}

Very large areas of presently non-forested lands are needed if significant quantities of new carbon are to be sequestered on the land. In the tropics, carbon sequestering rates tend to be high (Brown \& Lugo 1982) and vast areas of lands are degraded and in need of reforestation (Grainger 1988). It has been proposed that a combination of natural reforestation, tree plantations, and agroforestry practices be established on these degraded lands to sequester carbon (Sedjo \& Solomon 1989, Grainger 1990a, 1991, Winjum et al. 1992). Estimates of new forest plantations to absorb the entıre current annual net increase in atmospheric carbon (about $2.9 \mathrm{Pg}$ ) range from 465 million ha (Sedjo \& Solomon 1989) to 600 million ha (Grainger 1990a). Establishing such large new plantation areas within a reasonable time scale to mitigate climate change would probably not be feasible. Instead, Grainger (1990a) suggested that it would be more realistic, in light of the current tropical planting rate of about 1 million ha $\mathrm{yr}^{-1}$, to aim for an establishment rate of 2 to 3 million ha $\mathrm{yr}^{-1}$ of new plantations that would, if simultaneously implemented with actions designed to reduce deforestation rates and associated carbon emissions according to the scenarios described in Grainger (1990b), result in no net carbon emissions from tropical deforestation within $40 \mathrm{yr}$.

The above practices basically rely on planting trees on seriously degraded forest or lands not presently in forest. However, there is mounting evidence that very few of the lands presently in tropical forest are at their maximum (i.e. potential) level of biomass density, that is, nearly all tropical forests have been disturbed to some degree. Recent work (Brown \& Lugo 1992, Brown et al. 1992, Flint \& Richards 1993, Iverson et al.
1993) has shown, especially in tropical Asia, that most tropical forests contain a considerably lower biomass density than their potential, a result of human influences over many decades to centuries. A large proportion of this forest land is probably recovering towards its potential carbon stocks after logging or clearance, although regeneration could be interrupted by further clearance for shifting cultivation, or hindered by continued overlogging or log poaching. In most global assessments to date, these present forest lands have generally been considered to be mature and are, therefore, assumed to be in carbon steady state and play no role in the carbon cycle. As they are not at their maximum carbon density, existing tropical forest lands have a large potential to sequester additional carbon and increase the global biotic carbon store beyond the present, generally accepted values.

\section{Suitability and availability of lands to sequester carbon}

A major source of uncertainty is the extent of land which could be used in programs contributing to increased carbon sequestration. We distinguish here between lands that are technically suitable for such programs and those that are actually available. Tropical lands with the potential to sequester more carbon through management can be divided into 3 main classes: present forest lands, present agricultural lands, and degraded lands. The criteria for determining suitability and availability for carbon sequestering of these 3 classes are different and we analyze them separately. Our focus in this paper is on present forest lands.

We define present forest lands as being technically suitable if their present carbon stocks are less than their maximum. It is essentially the potential for additional biomass storage; we use the term primarily in the context of increasing the carbon store rather than the carbon sink because protection is the only management practice being considered (i.e. harvesting and long-term storage are not considered).

In reality, consideration of the 'best' management strategy over the landscape, based on the biophysical and the socio-economic characteristics of the region, using both the carbon sink and the carbon store approaches to carbon sequestration and mitigation (see above), is needed to fully assess lands for their technical suitability and actual availability for carbon sequestration projects. Only a portion of the technically suitable lands would, in practice, be available for use in carbon sequestration programs. We define actually available lands as those which are economically, politically, and socially acceptable for placement in the particular forested land use, such as protected forest, plantation, or intensive management. 


\section{METHODOLOGY}

The methodology developed to assess the potential for additional biomass storage on present forest lands in tropical Asia entailed the use of GIS modelling to generate index maps of potential and actual biomass density. These maps were generated by merging a suite of regional or global data bases. The difference between the potential and actual biomass density index maps could then be used as a measure of the technical suitability, or potential to sequester additional carbon across the area.

\section{Study area}

The area of study consists mainly of the continental portion of tropical South and Southeast Asia, and includes the following countries: Bangladesh, Cambodia (Kampuchea), India, Laos, Myanmar (Burma), Peninsular Malaysia, Sri Lanka, Thailand, and Vietnam. General descriptions of the biological and physical attributes of this region are given in Whitmore (1984) and Collins et al. (1991). The region is composed of extremely diverse vegetation formations, ranging from the deserts of northwest India to the moist and species-rich lowland forests of Peninsular Malaysia. Most of the continental diversity in vegetation classes can be attributed to rainfall patterns, including the total amount and its seasonality (Whitmore 1984). Edaphic and geomorphologic patterns are responsible for further differentiation of the vegetation and, consequently, land use of the region.

\section{Data bases}

The validity of our results is very much determined by the accuracy and reliability of the available large-area data sets upon which this work is based. Data were acquired from international agencies or automated by us. Data were processed with ARC/INFO, ERDAS, and GRASS software (Environmental System Research, Inc., Redlands, CA, USA; Earth Resources Data Analysis, Inc., Atlanta, GA, USA; U.S. Army Construction Engineering Research Laboratory, Champaign, IL, USA) on Sun Sparcstations, in Albers conical equal area coordinates. Quality control was exercised by multiple overlays and consistency checks of the data. It was not possible, however, to completely validate each polygon for each layer used in the analysis.

The databases used and much of the preprocessing are described in detail in Iverson et al. (1993) and will only be briefly described here

National and subnational boundaries. These data were extracted from the World Boundary Database-II, in vector form. The database was derived from 1:13000000 scale source maps, and was acquired from the United Nations Environment Program (Global Resource Information Database) in Geneva, Switzerland

Topography/elevation. These data originated from the U.S. National Geophysical Data Center and are raster data with a cell size of 5 minutes; they were acquired from the United Nations Environmental Program in Geneva, Switzerland. The data were rescaled in $15 \mathrm{~m}$ increments from $0 \mathrm{~m}$ (sea level) to ca $4000 \mathrm{~m}$.

Soils. The soil data originated from the Food and Agriculture Organization (FAO) source maps prepared between 1974 and 1978 at a scale of approximately 1:5000000. The data were obtained from FAO in Rome. Besides soil type, the map units also show texture and slope classes, each of which was mapped and evaluated separately.

Vegetation. A vegetation map of the region was prepared between 1981 and 1985 by FAO in collaboration with the Institute of International Mapping of Vegetation, Toulouse, France (FAO 1989). The maps were largely derived from visual interpretation of Landsat imagery and other maps from the period around 1980 , with a resulting vector map of $1: 5000000$ scale. We obtained this digital map from FAO. Twenty-six landuse/vegetation classes were delineated. We identified 13 of these classes to be forests, which we further grouped into 6 commonly recognized classes: closed forests, secondary forests, shifting cultivation/forest fallows, open forests, mixed forest mosaics, and shrublands. We used this reclassified forest map to represent the present forest lands.

Meteorological station data. FAO provided monthly meteorological information for 593 stations in the region. These data, which included monthly precipitation, maximum, minimum, mean daily, and mean nightly temperatures, day length, and vapor pressure, were used to calculate a climate index (modified Weck's climate index; Iverson et al. 1993). The climate index and precipitation data were interpolated over the entire region using a regularized thin-plate spline technique (Mitas \& Mitasova 1988)

Ecofloristic zones. These data, used for summary purposes, were developed by and obtained from FAO, also in collaboration with the Toulouse group. Thirtysix ecofloristic zones were distinguished for the region based on floristic, climatic, physiographic, and edaphic factors at a scale of 1.5000000 . We used the attributes of the zones to reclassify the map into 5 zones more akin to those of Holdridge (1967); the 5 zones are the lowland moist, lowland seasonal, lowland dry, montane moist, and montane seasonal zones.

Population data. Raw population data, reported by subnational district or state to FAO, were used to 
derive a population density map of the region. Data on population density were assigned. to the largest city of the subnational unit, and interpolation resulted in the population density decreasing away from the main population center until it was influenced by the adjacent population centers.

Global vegetation index (GVI). These data were provided in raster format with a pixel size of approximately $16 \times 16 \mathrm{~km}$ at the equator. A total of 45 monthly mean composites of a normalized difference vegetation index (NDVI), dating from July 1986 to December 1989, were processed in the image analysis system. The NDVI, as a ratio of differences, can be assumed to correct for most atmospheric and radiometric variations in time and space (Tarpley et al. 1984). The GVI data were obtained from the U.S. Army Construction Engineering Research Laboratory in Champaign, Illinois.

\section{Determination of potential carbon sequestration index}

There have been several attempts to map potential vegetation globally (e.g. Neilson et al. 1992, Prentice et al. 1992), particularly through the use of climatic variables. The work on mapping Holdridge life zones (Holdridge 1967) as indicators of potential vegetation is an example of this effort (Emanuel et al. 1985). We considered this approach but rejected it because, for tropical Asia, the life zone map did not correspond well (in scale or spatial distribution) with other climatic data bases we use and have confidence in. Furthermore, an appropriate data base on carbon densities of the potential forest vegetation is sorely lacking (cf. e.g. Brown \& Iverson 1992). Because of these problems, we used a different approach based on our earlier work (Iverson et al. 1993).

We first estimated an index of potential, or maximum, carbon density (i.e. without human and natural disturbance) for present forest lands based on the biophysical characteristics of the region. We then used this index to derive a relative score of its potential sequestration capacity. Essentially, our technique involves the integration of each of the data bases intro- duced above into a common data base, followed by relative assessments within and between each data layer as to their capacity to support forest biomass. This assessment was done in an iterative fashion and the final scheme was arrived at by first establishing a general weighting from Whitmore (1984), comparing model results to known localities (inventories, other literature, and/or personal experience), and by adjusting the influence among climatic and geomorphologic controls to yield the most realistic map of potential carbon sequestration index (PCSI). Obviously, many assumptions were made in weighting each layer as insufficient data were available for quantifying each component. The assumptions for each layer are presented in detail in Iverson et al. (1993). The final scheme was equally based on a climatic component and a geomorphological component, through an additive GIS model, and a 0 to 100 score (the PCSI) was derived for each pixel of the study area (Fig. 1). The GIS processing summed the points for each pixel based on the range of points possible for each of several data layers; the higher the aggregate score, the higher the PCSI (Iverson et al. 1993). The climate component was equally influenced by the mean annual precipitation (25 possible points) and the modified Weck's climatic index (25 points). The geomorphological component was based on soil texture (13 points), soil quality which was primarily based on soil depth (12 points), slope angle (13 points), and elevation (12 points). The modelled PCSI map (indices ranging from about 20 to 100 ) was reclassified into 6 equal width classes for display and summarization purposes.

\section{Determination of actual carbon sequestration index}

The actual amount of carbon stored in present forest lands is represented by the actual carbon sequestration index (ACSI). We used 2 independent approaches to estimating ACSI in this study, resulting in 2 mapped scenarios of technical suitability of present forest lands; these were a degradation approach and a remote sensing approach (Fig. 1).
Fig. 1. Flow chart depicting methods to derive potential carbon sequestration index (PCSI), actual carbon sequestration index (ACSI), and technical suitability for sequestering carbon in tropical forests. ACSI-d and ACSI-g refer to ACSI scores derived from the degradation and GVI models, respectively (see text)

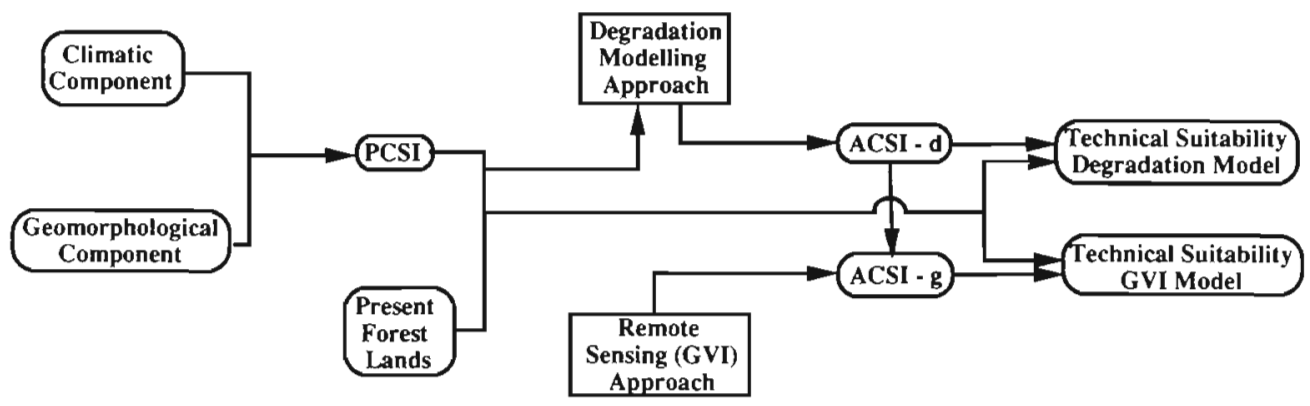


Degradation model. This approach is based on the work of Iverson et al. (1993) to assess biomass densities for forests of tropical Asia. They assumed that the degree to which forests are degraded (i.e. exhibit reduced biomass density) is related to population density and climate zones. In general, forests in dry areas would be expected to be more degraded than forests in moist areas at a given population density because vegetative growth, and consequently resilience to disturbance, will be slower in the drier climatic regions.

Degradation ratios were calculated for forests at the subnational level across the region for which forest inventories have been conducted in the recent past. The inventories were conducted in various parts of Bangladesh, Peninsular Malaysia, Sri Lanka, Thailand, Vietnam, and India, and occurred at different times from the early 1960 s to the mid-1980s. Biomass density for each of 42 inventory areas was estimated from stand or stock tables (number of trees ${ }^{-1}$ or volume $e^{-1}$ by diameter classes) according to the methods developed in Brown et al. (1989). The degradation ratio equals an estimate of the actual biomass density of the forests in a given subnational unit (estimated from the inventoried areas) divided by the mean potential biomass density (a calibrated PCSI; cf. Iverson et al. 1993) derived from biophysical parameters for the same subnational unit. The degradation ratio can thus be thought of as the proportion of the potential biomass or carbon density in existence at a given time in each inventory location.

The calculated degradation ratios by subnational unit and their corresponding population densities (taken from the time nearest to the time of the forest inventory of each unit) were stratified by 3 climate regimes (moist, seasonally moist, dry) and subjected to least squares regression analysis. Three significant linear regression equations were obtained, with $r^{2}$ values of $0.41,0.35$, and 0.50 for dry, seasonal, and moist climate regimes, respectively. The slopes for the regression equations indicated that the rate of forest degradation with increasing population density was steepest in the dry followed by the seasonal and then by the moist zones (Iverson et al. 1993). These equations were used, along with the map of population density (1980 data), to derive a map of degradation ratios for the study region. This map was then used with the PCSI map to calculate the ACSI (hereafter referred to as ACSI-d) across the entire area.

Global vegetation index model. The second method for estimating ACSI used the GVI data from NOAA (National Oceanic and Atmospheric Administration) satellites. The GVI is too coarse for applications at fine scales, but it has been useful for some continentalscale applications (e.g. Goward et al. 1985, Tucker et al. 1985a, b. 1986).
First, we extracted forested pixels, as masked by the 1980 present forest lands map. To smooth some annual fluctuations in vegetative response to climatic variation, we used 4 yr of monthly composited GVI data (1986 to 1989 ) to arrive at an overall annual mean for each pixel. As the forest/nonforest mask was based on data that were 6 to 10 yr older than the GVI data, it is likely that some of the forests represented by the present forest lands map have been deforested in the interim, and may contribute to an error term in the analysis. On the other hand, the GVI data could reflect a more recent assessment of actual forest cover and, consequently, technical suitability.

As the GVI is a unitless number, we needed to rescale it into units that could be related to ACSI and PCSI. It was not possible to relate GVI to ground-based information (such as the inventory-based biomass density estimates) directly as the inventories were up to 25 yr older than the GVI data. To scale the GVI to the same units being used in our analysis, we applied least squares regression analysis to the GVI and ACSI-d. As the only purpose of the ACSI-d data was to convert GVI data into index units, the GVI assessment can be considered independent from the degradation model assessment.

We first assessed the overall correlation of the GVI with ACSI-d. We systematically sampled GVI and ACSI-d pixel pairs at an intensity of $1 / 16$ across all forested pixels of the region ( $n=1232)$, and linearly regressed them against each other. The relationship was highly significant but the data were widely scattered $\left(\mathrm{r}^{2}=0.263, \mathrm{n}=1232, \mathrm{p}<0.0001\right.$; Fig. 2a). This result shows that one cannot reliably determine ACSI for any particular pixel on the ground, but that there is good predictability when the entire landscape is considered as a whole.

To scale each GVI pixel, we took the mean ACSI-d score from the forested pixels for each of 24 integer GVI levels (digital numbers of 6 to $29, n>100$ ), and linearly regressed them against the GVI. In this case, the GVI was found to be highly correlated with the mean ACSI-d $\left(r^{2}=0.90, n=23, p<0.0001\right.$; Fig. 2b). The relationship plateaus and even declines near the high end of GVI (Fig. 2b). The vegetation classes with high GVIs but lower than expected ACSI-d are dense forest with shifting cultivation and secondary forest with shifting cultivation. These classes usually contain closed forests with vigorously growing trees that reflect very highly in the near-infrared portion of the spectrum and thus in the GVI. However, because of the nature of the forest land use (cleared plots to various-aged forest plots), these forests rarely have high biomass densities. Thus, the GVI overestimates the ACSI for these classes. Because of the continental 

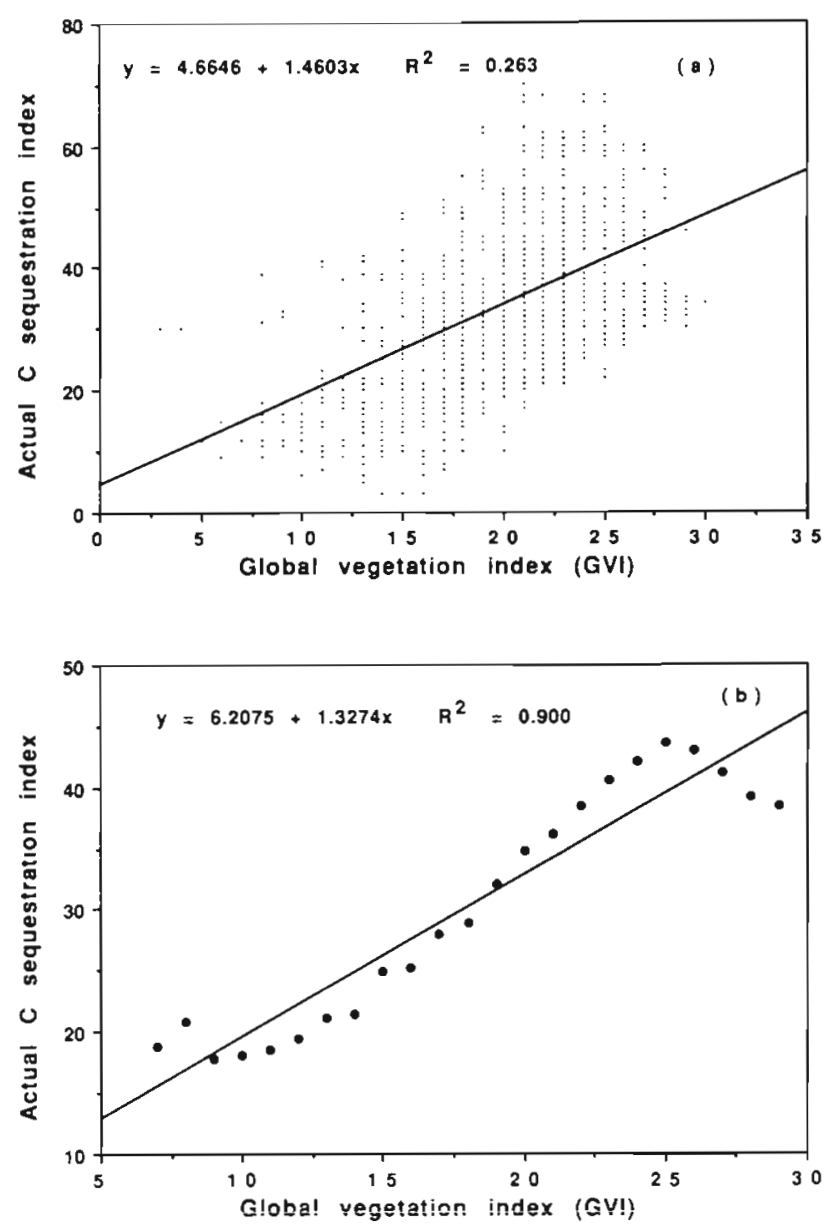

Fig. 2. Relationship between global vegetation index (GVI) and actual carbon sequestration index (ACSI) from the degradation model: (a) GVI/ACSI-d scores for individual pixel pairs for forest lands $(n=1232)$, (b) mean ACSI- $d$ for each GVI integer value for forest lands ( $n=23$ )

level of analysis used here and the high correlation achieved, we felt justified in using this relationship to assign ACSI scores to each GVI pixel.

Mean GVI is generally more highly correlated with leaf area index (LAI) than with biomass density (Running et al. 1987, Box et al. 1989). The GVI/ACSI-d relationship apparently holds in this study because there is a general relationship between standing biomass and LAI across a wide diversity of forest types such as in tropical continental Asia. GVI historically has not been shown to be extremely useful in distinguishing among forest types because the sensor tends to saturate at the higher LAI levels common in forested systems. However, the forests in this region are extremely varied with respect to LAI and biomass density, ranging from dry tropical forest and scrublands (with low GVI, ACSI-d, LAI, and biomass density) to lowland moist tropical forest (with high
GVI, ACSI-d, LAI and biomass density). Only in places such as shifting cultivation forests do major departures from this overall continuum occur. A similar pattern, with a significant asymptotic relationship between GVI and net primary productivity, was found by Box et al. (1989); these authors did not, however, find a significant relationship between GVI and standing biomass over these same sites.

To partially validate the use of the above-established statistical relationship between ACSI-d and GVI, a regression of mean ACSI-d and mean GVI by 13 forested vegetation classes was conducted (Fig. 3). In general, there was good correlation with expected results: the lowest values are for mangrove forests, open forest types have intermediate values, and the highest values are for secondary forests, mosaics of forest and shifting cultivation, and a mosaic of dense and secondary forests (Fig. 3). Two major outliers existed in the relationship: (1) the periodic swamp forest, which has a GVI lower than expected because water, when present in the swamps, has an extremely dark spectral signature (low GVI), and a high ACSI-d because of low human population pressure on these flooded forests; and (2) the mixture of thickets, scrub forest, and savanna, which is harder to explain, but it is a marginal forest class with much of the annual signature coming from light-colored senesced grass and bare ground [light-colored surfaces tend to cause the GVI to go above the expected irends (Holben 1986), and may be responsible for some of the abnormally high GVI values for this vegetation class]. Errors in identification of vegetation classes on the original FAO vegetation map may also be responsible for deviations away from the expected.

\section{Determination of technically suitable present forest lands}

Once the PCSI and the 2 estimates of ACSI were mapped (all with potential scores of 20 to 100), the mapping of technically suitable lands was simply the result of subtracting ACSI from PCSI. The PCSI minus ACSI scores were then reclassified into 6 classes of technical suitability. The technical suitability classes are therefore related to the amount of carbon that could be sequestered in forests if they were protected or managed in such a way as to allow them to accumulate biomass up to their potential.

Based on related research (Iverson et al. 1993), which calibrated the PCSI and ACSI to units of biomass carbon density, the lowest class is equivalent to less than $50 \mathrm{Mg}$ of additional $\mathrm{C} \mathrm{ha}^{-1}$, with subsequent classes increasing by an additional $50 \mathrm{Mg} \mathrm{Cha}^{-1}$ up to 


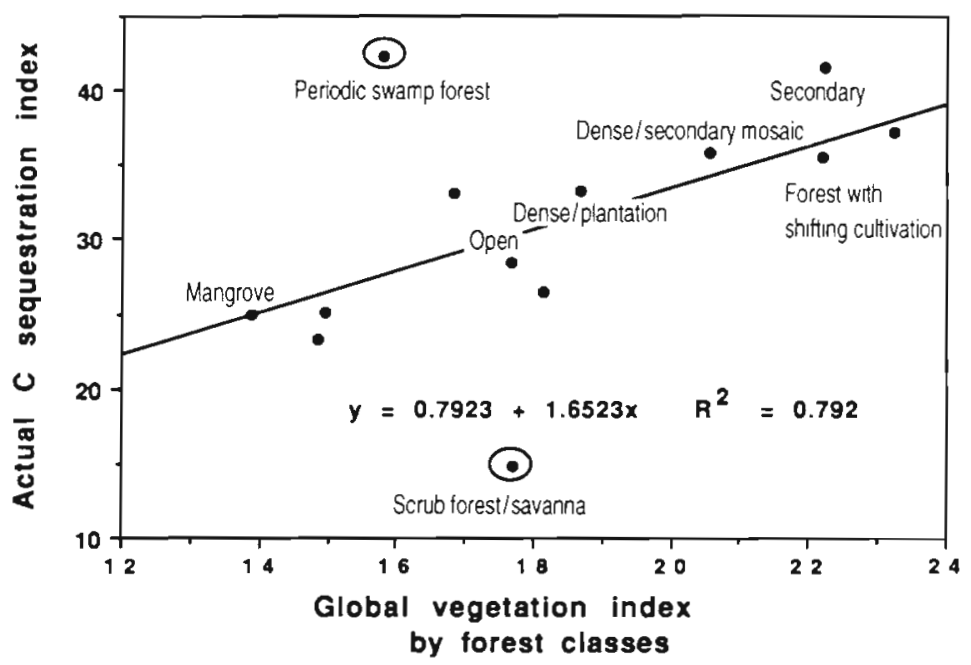

Fig. 3. Relationship between global vegetation index (GVI) and actual carbon sequestration index (ACSI) from the degradation model, aggregated across 13 forest vegetation types. The 2 circled points are outliers and were removed for the regression equation

class 6 which is equivalent to $>250 \mathrm{Mg} \mathrm{C} \mathrm{ha}^{-1}$. These values were used to produce a first order estimate of the potential or upper limit of carbon that could be sequestered in technically suitable present forest lands.

\section{RESULTS AND DISCUSSION}

\section{Potential carbon sequestration index}

The PCSI map, reclassified into 6 classes, shows the highest PCSI in the more humid climates, including Peninsular Malaysia, Sri Lanka, Bangladesh, northeast India, and the western coastlines of India, Thailand, and Myanmar (Fig. 4). The lowest PCSI values were found in the drier portions of western India and the mountainous portions of northern India (Fig. 4). The locations of medium or higher PCSI would be the places that could store the most carbon when operating under no constraints due to the presence of humans.

The ecofloristic zone that occupies the largest area overall is the lowland seasonal zone, dominated by medium to high PCSI scores (Fig. 5a). The lowland moist zone has a smaller area overall, but proportionally more land in the medium high to very high rankings. By contrast, the lowland dry and montane zones have proportionally more land with medium to low PCSI values (Fig. 5a).

When evaluated by country, India has by far the largest area of present forest land, and most of its land has medium to low PCSI rankings, though a sizeable quantity of land (about 15\%) has high rankings (Figs. 4
\& 5b). The area of Peninsular Malaysia is relatively small, but essentially all of it has high or very high PCSI rankings.

\section{Actual carbon sequestration index}

Nearly all of the ACSI scores for present forest lands, obtained by either the degradation or GVI method, fell into the 2 lowest ranking classes (Fig. 6), whereas the majority of the PCSI scores were medium and higher scores. The 2 methods of deriving ACSI were in general agreement, with the majority of present forest land area being ranked either very low or low. The ACSI-d scores, however, did have some higher ranking pixels, whereas the ACSI$g$ did not. In effect, the regression equation used to calculate ACSI-g smoothed the data.

Most present forest land was in the lowland seasonal zone, with about half of its land area being ranked very low and the other half ranked low to medium high (Fig. 6a). The lowland moist zone had the lowest proportion of land ranked as very low, while the lowland dry zone was essentially all ranked in the lowest ACSI class.

The country with the largest present forest land area was India, followed by Myanmar, Thailand and Laos (Fig. 6b). The highest ACSI scores (from either method) were found in southern Laos, northern Cambodia, northern Thailand, and northern and western Myanmar. The ACSI ranked in the lowest category in over two-thirds of India's forests, whereas Cambodia, Laos, Sri Lanka, and Myanmar had large portions of their forests with ACSI scores in higher categories (Fig. 6b).

\section{Estimates of technically suitable lands}

Comparison of two methods of assessing technical suitability

The mapped distribution of technically suitable lands resulting from the degradation model (Fig. 7a) showed remarkable similarity to that resulting from the GVI model (Fig. 7b). The largest departures between the 2 methods were found in (1) the 3 easternmost countries of Cambodia, Laos, and Vietnam, where the degradation model yielded lower ratings than the GVI model, (2) India, where the northeastern states had higher values and the eastern coastal region had lower values in the GVI model, and (3) Peninsular Malaysia, where more pixels of high and very high technical suitability were scored under the GVI 


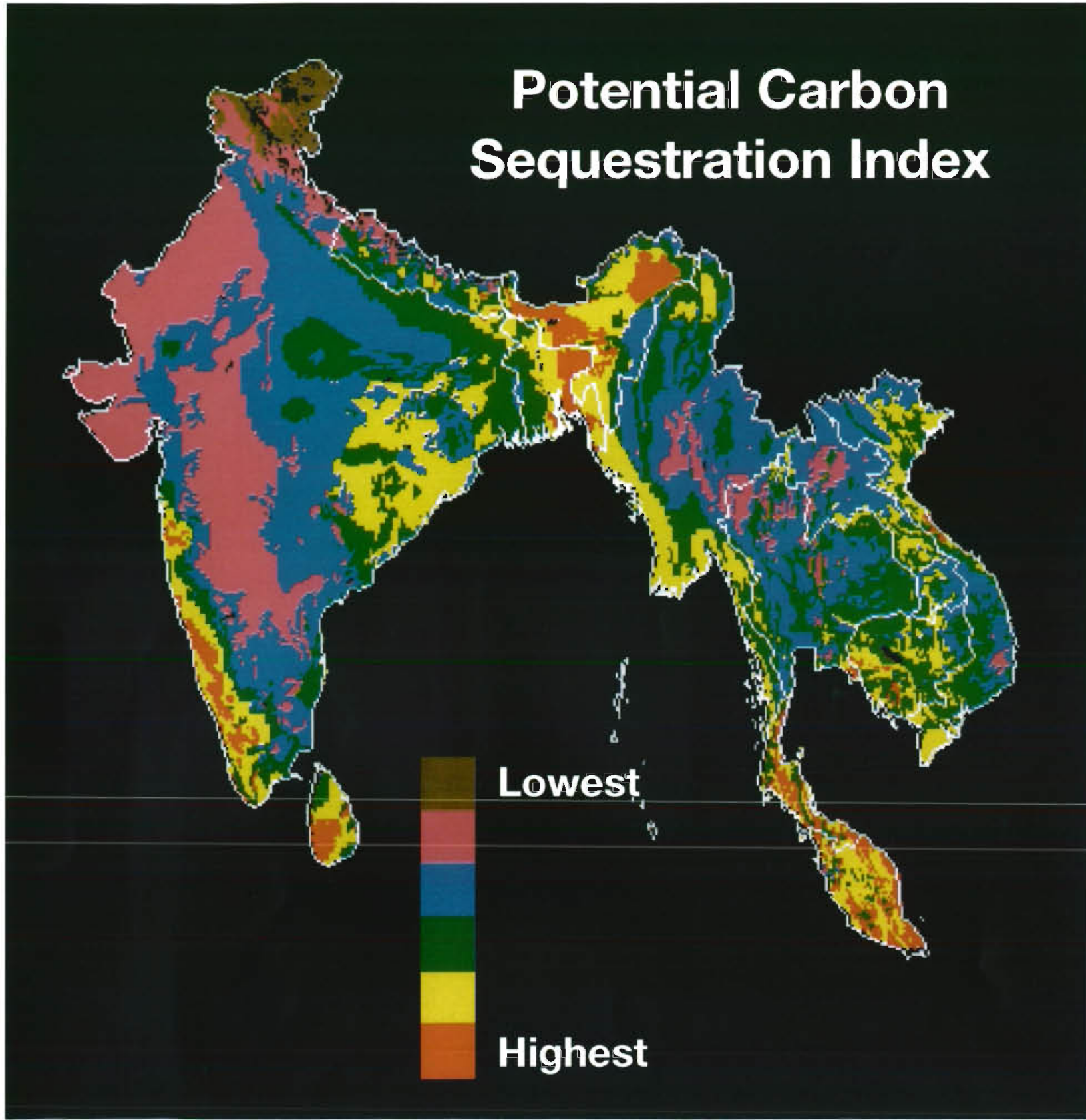

Fig. 4. Map of potential carbon sequestration index (PCSI)

method (Fig. 7, Table 1a). The differences in age of the data (the GVI dates to between 1986 and 1989, while the degradation model is designed for 1980) could partly explain the departures between the 2 methods; however, it is difficult to confirm this because of the coarseness of the GVI data.

The overall similarity between methods partially validates the results of each because they are independently derived estimates. However, the GVU/ACSI relationship may not hold in regions of less heterogeneity of forest types because of sensor saturation in highly productive forest systems. As multi-date data of higher spatial and spectral resolution become readily available over continental regions, refinements in the methodology and specificity of results are likely to improve. These initial results are, however, quite promising.

Technical suitability by country

In general, the areas of highest suitability are found in Peninsular Malaysia and the eastern and northeastern parts of India. The easternmost countries (Vietnam, Laos, Cambodia) generally have the lowest technical 

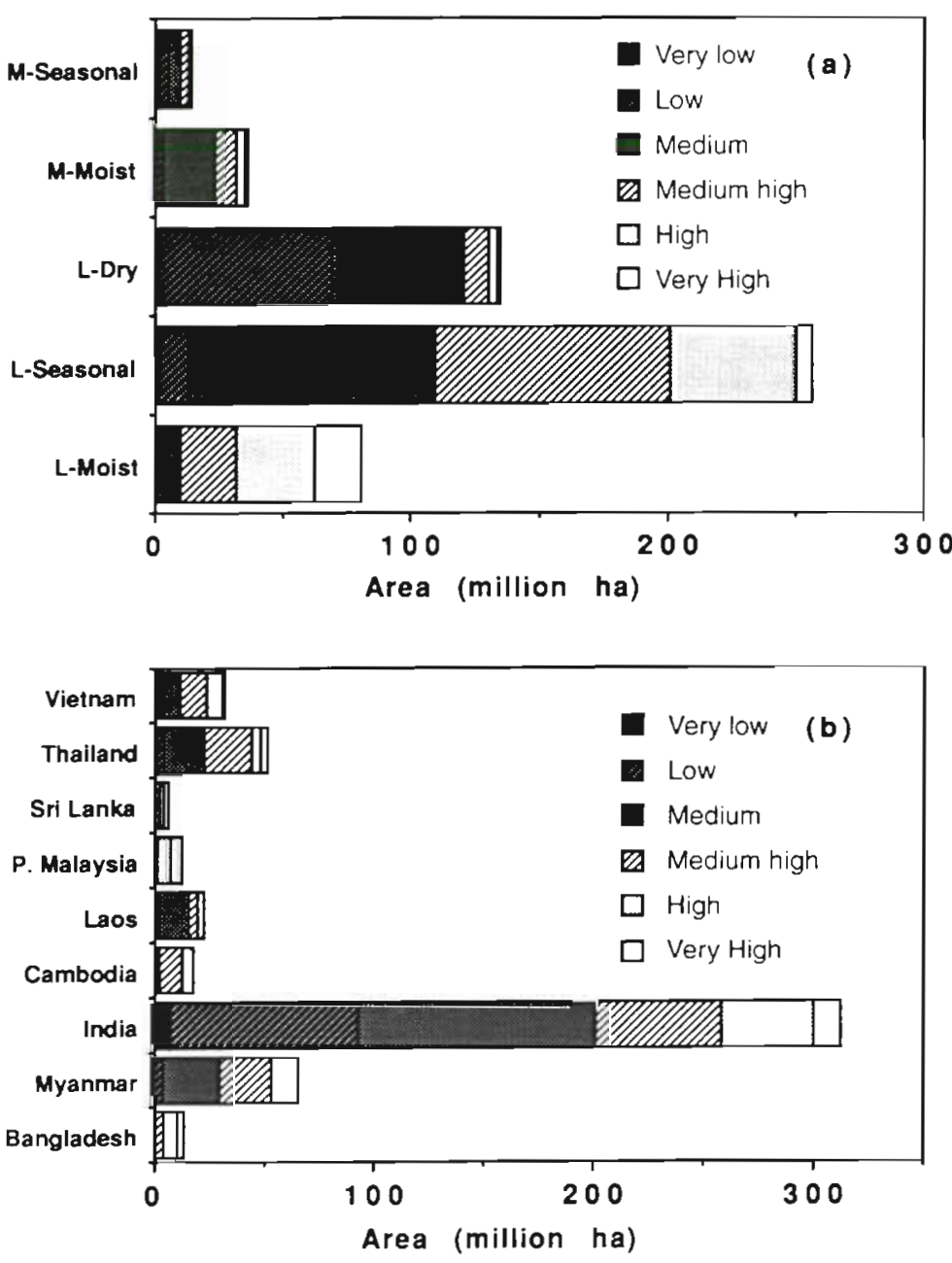

Fig. 5. Summary statistics of potential carbon sequestration index (PCSI) by (a) ecofloristic zone (L: lowland; M: montane) and (b) country

suitability ratings in that only a very small proportion of the forest land scored medium high or higher (Fig. 7 , Table 1a). Because their forests appear to be less disturbed due to low population pressure, the difference between PCSI and ACSI is relatively small. By contrast, Peninsular Malaysia has the highest proportion of land with medium high or higher technical suitability 15.7 million ha, or $88 \%$ ). This statistic, however, does not mean that Peninsular Malaysia's forests are overly degraded (Brown et al. 1993), Rather, a large portion of its forests are managed for timber production (Yusof 1988), which maintains their average carbon density substantially below their high potential (Fig. 4). India, with its huge expanses of land, has the largest absolute amount of land with relatively high suitability (29.4 million ha), primarily in northwest India (Fig. 7, Table 1a). On the other hand, because of the lower PCSI in the drier parts of India, the proportion of land with medium high or higher technical suitability is only $39 \%$
Technical suitability by ecofloristic zone

With respect to ecofloristic zones, most present forest lands are in the lowland seasonal zone. Most of the forest land with medium high or higher technical suitability, totalling an estimated 25.7 million ha $159 \%$ of all forest land rated medium high or higher), is also located in this zone (Table 1b). The lowland moist zone forests, however, have the highest proportion of land with medium high or higher suitability (17.7 million ha out of a total of 43.3 million ha, or $41 \%$ ). By contrast, the lowland dry and montane zones did not score high with respect to technical suitability, mostly due to their inherent low potential carbon sequestration capacity.

\section{Technical suitability by vegetation class}

Most of the present forest lands in tropical Asia are occupied by closed, open, and shifting cultivation forests; secondary forests, forest mosaics, and shrublands occupy only about $10 \%$ of the total area (Table $1 \mathrm{c}$ ). For the 3 dominant vegetation classes, about $75 \%$ of the area (113 million ha) is ranked medium to very low in terms of its suitability for carbon sequestration; about $10 \%$ only is ranked in the high and above classes. About $50 \%$ of all the land of medium high or higher technical suitability ( 24.3 million ha) occurs in the closed forest vegetation class alone. These forests are also the ones with the highest proportion of their land labout $30 \%)$ in the medium high or higher classes. Sizeable portions of medium high and higher technically suitable land can also be found in open forests ( 8.7 million ha) and shifting cultivation ( 7.3 million ha) forests.

Estimates of carbon sequestration

The first order estimate of the amount of carbon that potentially could be sequestered in aboveground biomass of the technically suitable present forest lands, based on the work of Iverson et al. (1993), is approximately $15 \mathrm{Pg} \mathrm{C}$. This value translates into an average quantity of about $88 \mathrm{Mg} \mathrm{Cha} \mathrm{hat}^{-1}$ that could be sequestered across all present forest lands in the region. This amount compares to an average maximum. carbon stock in present forest lands of $185 \mathrm{Mg} \mathrm{ha}^{-1}$ with a range of 25 to more than $300 \mathrm{Mg} \mathrm{C} \mathrm{ha}^{-1}$. Slightly 

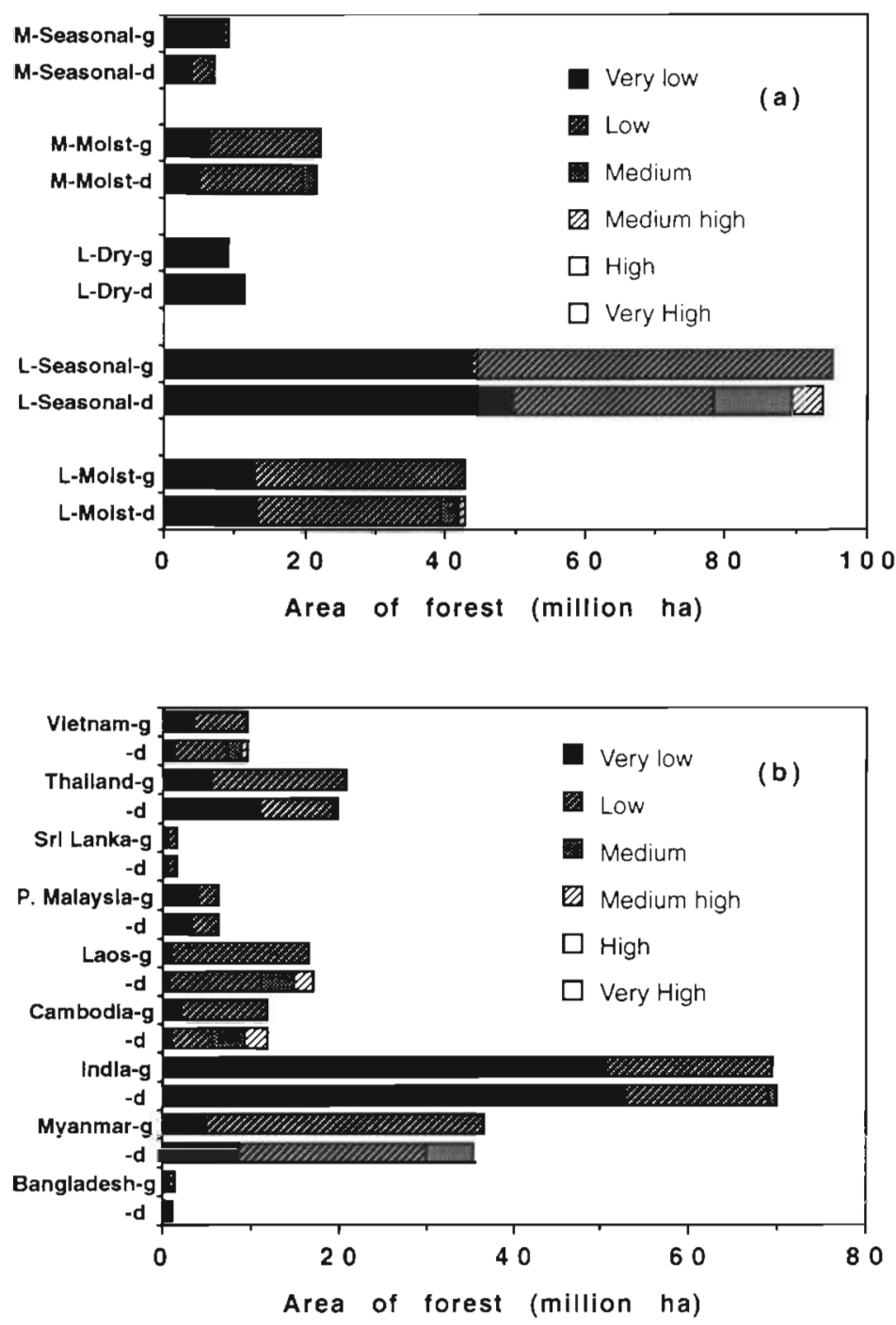

Fig. 6. Summary statistics of actual carbon sequestration index (ACSI), according to the degradation (d) and global vegetation index (g) models, by (a) ecofloristic zone (L: lowland; M: montane) and (b) country. Ranking classes are reported in identical units to those reported for PCSI in Fig. 5

\section{Sources of error}

This paper has presented an estimate of the amount and distribution of present forest lands which are technically suitable for carbon enhancement. This estimate is subject to error owing to both methodology and data limitations; with improved data (quality and resolution), better estimates will be possible. Ongoing research on this topic will focus on 2 countries (Thailand and Peninsular Malaysia) in the region where higher resolution data are available and errors in the analysis are expected to be reduced.

At this juncture, error in the analysis come from 3 main sources. (1) There is inherent error in the spatial data due to inaccurate maps or maps of insufficient detail. For example, results of our analysis of the GVI by forest classes versus the ASCI-d indicated potential errors in the vegetation map. (2) There is the potential for systematic errors in the modelling of the PCSI caused by inappropriate weighting schemes that we used for the input variables, or there may be other factors that are totally overlooked and not incorporated into the model. (3) There is error associated with applying imperfect regression equations across the landscape. This type of error applies to the degradation index versus population density relationships where the $\mathrm{r}^{2}$ and degrees of freedom were low, and to the GVI/ACSI relationship which was also less than perfect. Despite these sources of error, we believe these first regional maps of technical suitability are conceptually correct, adequate for first order regional planning, and available for improvement as better data come on line. less than a third $(31 \%)$ of the present forest land area could sequester up to a maximum of only $50 \mathrm{Mg} \mathrm{Cha}^{-1}$ additional carbon, indicating that, although disturbed, they are not presently at a substantially lower level of carbon than their potential. At the other end of the spectrum, about $5 \%$ of the forest lands are presently very much lower than their maximum carbon stocks and these lands could sequester carbon on the order of 150 to $250 \mathrm{Mg} \mathrm{ha}^{-1}$ (the high to very high rankings). The remainder of present forest land $(64 \%$ of forest areaj falls in the intermediate range, with a possible 50 to $150 \mathrm{Mg} \mathrm{ha}^{-1}$ of additional carbon sequestration.

\section{Planning for climate change mitigation}

Estimating the extent of technically suitable tropical forest lands in this way has applications to global climate change mitigation programs. Lands which are nominally forested but whose actual carbon density is markedly less than their potential carbon density could be considered highly technically suitable for either plantation establishment or managed natural forest regeneration. This could increase the size of the global biotic carbon sink. Forest lands whose actual carbon density is a larger fraction of their potential carbon density could receive suitable management treatments 


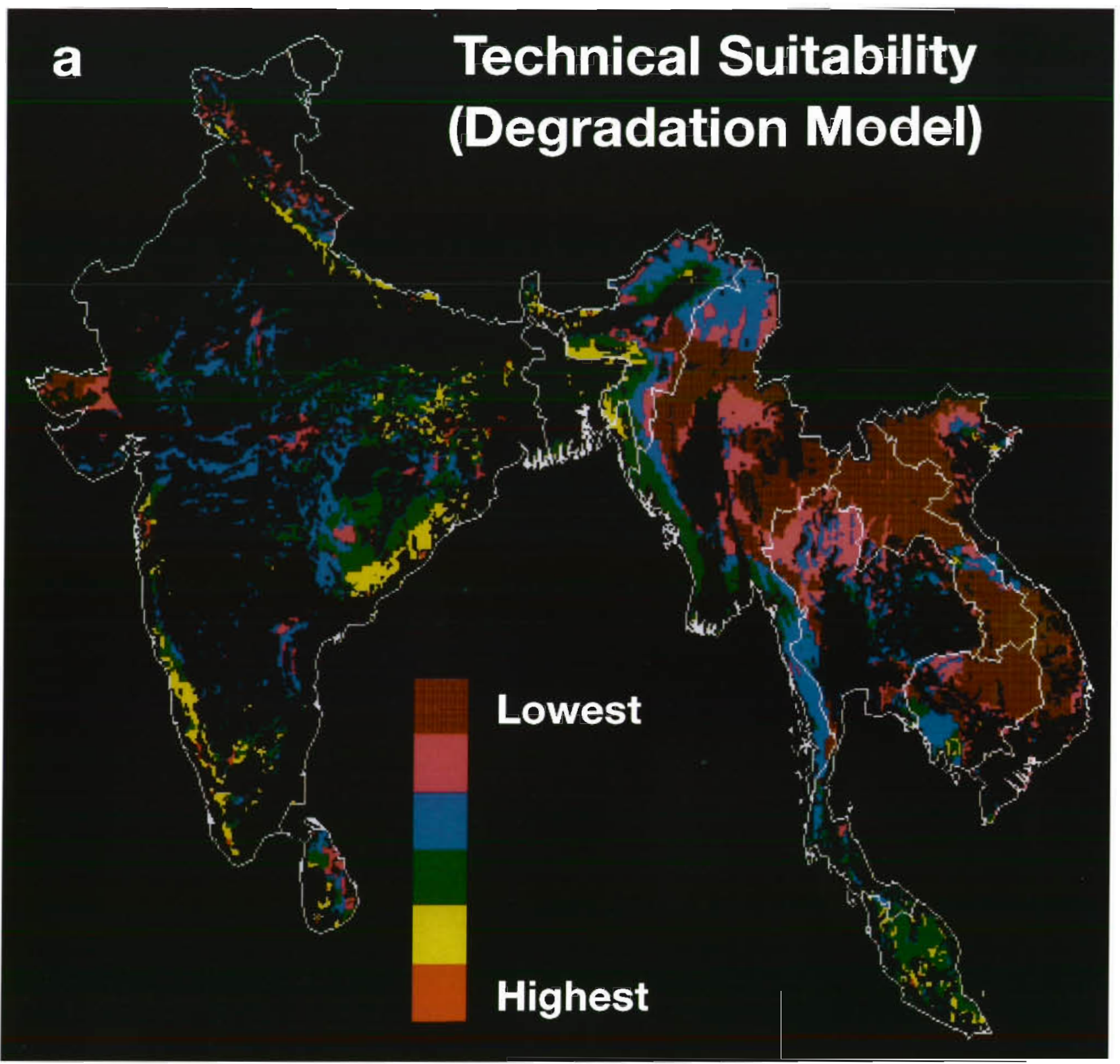

Fig. 7 (above and facing page). Maps of technical suitability to sequester carbon in tropical forests, according to (a) the degradation model and (b) the GVI model

that would enable them to move closer to this potential value.

However, all that can be said about technically suitable forest lands, as defined using the present methodology, is that they could benefit from increased protection to give maximum opportunity for their carbon stores to increase by natural regeneration and regrowth. There is no indication whether managed regeneration/ regrowth is already occurring, whether it could occur given some change in the forest management regime, or whether more interventionist measures (e.g. reforestation or afforestation) are needed.
These qualifications are needed because, of the estimated 152 million ha of tropical closed and open forests in our study area of tropical Asia in 1980 , 17.7 million ha were logged or managed forest undergoing regeneration (FAO 1981). Not included in the forest area total were another 45.5 million ha of forest fallow: secondary forest regenerating on abandoned shifting cultivation plots but still under a shifting cultivation management system (FAO 1981). Both classes of forest cover would have an actual biomass density substantially less than their potential biomass density, but the logged or managed forests could be moving 


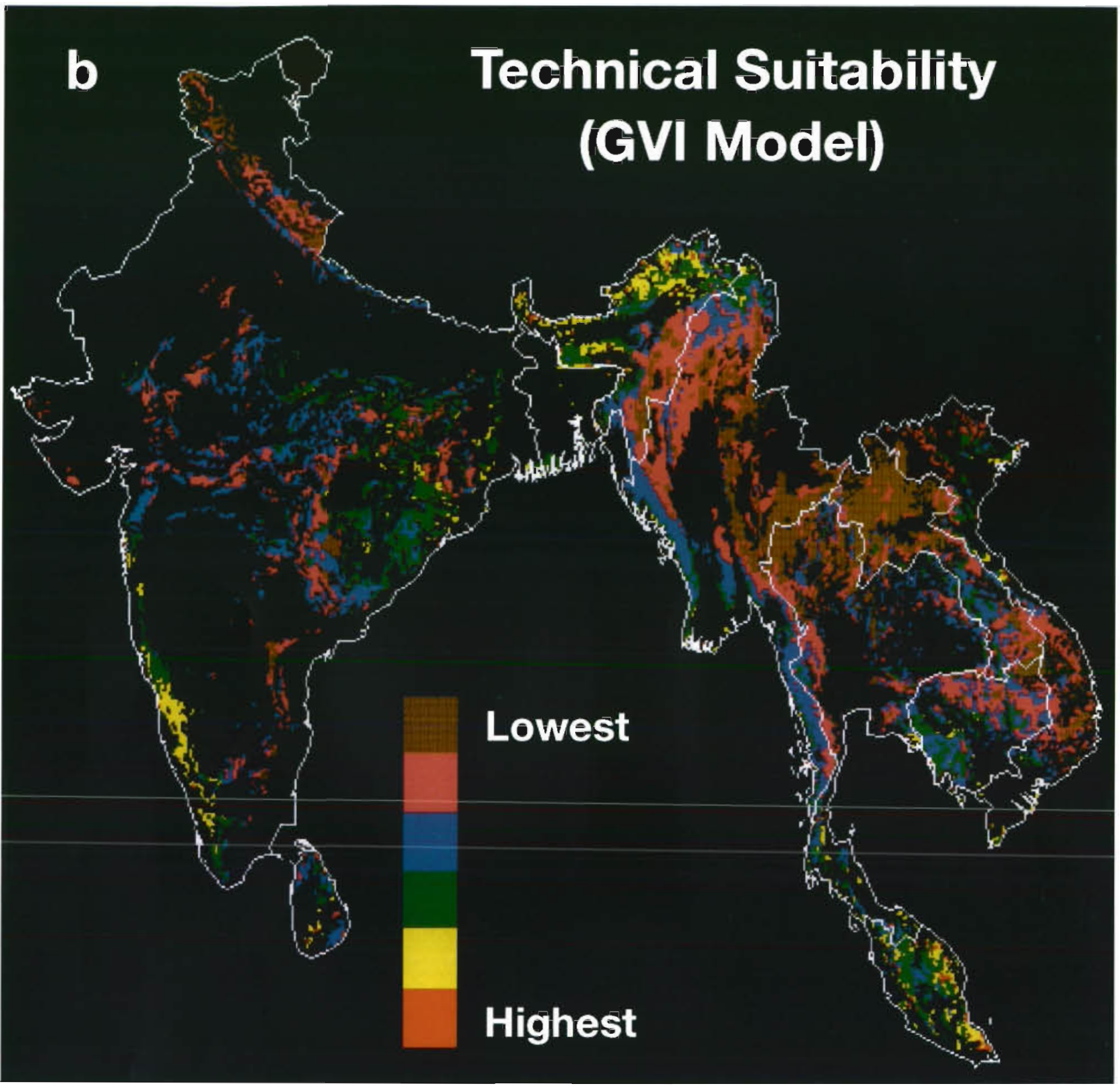

back towards their potential value under varying degrees of management and, moreover, represent a major carbon sink. Given sustainable management, although this cannot always be assumed (Grainger 1993a), forest fallow is not a net carbon sink but it does represent a stable long-term carbon store of magnitude equal to the mean amount of carbon stored over the course of the fallow and cropping periods.

These points suggest the need for care when using an index of degradation to estimate the area of tropical land technically suitable for carbon enhancement by increasing its carbon sequestration rate and/or carbon storage. A significant proportion of land currently below its potential carbon density is logged forest and does not need any additional treatment beyond an improvement in protection (e.g. in Peninsular Malaysia). So it is important to recognize different levels of technical suitability, from merely strengthening forest protection, at one end of the spectrum, to intensive afforestation programs at the other. We are extending our methodology to allow differentiation between these. An equally significant portion of land is forest fallow, which, if protected from human influences, could also return to its potential carbon density. Unfortunately, because it forms part of the area under shifting cultivation, which is widespread throughout the humid tropics, this is not presently a feasible option. So the land may be technically suitable for carbon 
Table 1 Average (degradation and GVI methods) area of present forest lands (million ha) ranked according to their technical suitability for carbon sequestration. Data are reported by (a) country, (b) ecofloristic zone, and (c) vegetation class. Values in parentheses represent results from the degradation and GVI, models, respectively. L: lowland; M: montane

\begin{tabular}{|c|c|c|c|c|c|c|}
\hline & Very low & Low & Medium & Medium high & High & Very high \\
\hline \multicolumn{7}{|l|}{ (a) Country } \\
\hline Bangladesh & $0.1(0.0,0.1)$ & $0.0(0.0,0.0)$ & $0.3(0.0,0.5)$ & $0.7(0.9,0.5)$ & $0.3(0.3,0.2)$ & $0.1(0.0,0.1)$ \\
\hline Cambodia & $4.0(7.2,0.8)$ & $2.6(1.5,3.6)$ & $3.6(2.3,4.9)$ & $1.6(0.8,2.4)$ & $0.2(0.1,0.2)$ & $0.1(0.0,0.1)$ \\
\hline India & $9.6(3.7,5.9)$ & $12.4(8.0,16.8)$ & $24.0(26.5,21.4)$ & $20.3(22.1,18.4)$ & $8.5(10.5,6.4)$ & $0.6(1.0,0.6)$ \\
\hline Laos & $11.7(14.9,8.5)$ & $2.7(1.2,4.1)$ & $1.8(0.6,3.0)$ & $0.5(0.1,0.8)$ & $0.0(0.0,0.0)$ & $0.0(0.0,0.0)$ \\
\hline Myanmar & $11.7(13.5,9.9)$ & $10.0(6.8,13.1)$ & $10.6(10.6,10.6)$ & $7.5(4.9,2.6)$ & $0.2(0.0,0.3)$ & $0.1(0.0,0.2)$ \\
\hline Peninsular Malaysia & $0.1(0.0,0.1)$ & $0.0(0.0,0.0)$ & $0.7(0.3,1.0)$ & $3.9\{4.8,3.0\}$ & $1.4(1.1,1.7)$ & $0.4(0.1,0.6)$ \\
\hline Sri Lanka & $0.1(0.1,0.0)$ & $0.3(0.4,0.1)$ & $0.7(0.4,0.9)$ & $0.4(0.3,0.4)$ & $0.2(0.2,0.2)$ & $0.1(0.0,0.1)$ \\
\hline Thailand & $5.0(4.4,5.5)$ & $6.2(6.7,5.7)$ & $7.0(6.5,7.5)$ & $1.9(2.2,1.6)$ & $0.3(0.1,0.4)$ & $0.1(0.0,0.1)$ \\
\hline Vietnam & $4.0(6.3,1.6)$ & $4.6(1.6,3.9)$ & $1.4(0.9,1.8)$ & $1.1(0.5,1.6)$ & $0.3(0.2,0.4)$ & $0.1(0.0,0.2)$ \\
\hline Total $^{d}$ & $41.5(50.1,32.4)$ & $38.8(26.2,47.3)$ & $50.1(48.1,51.6)$ & $37.9(36.6,31.3)$ & $11.4(12.5,9.8)$ & $1.6(1.1,2.0)$ \\
\hline \multicolumn{7}{|l|}{ (b) Ecofloristic zone } \\
\hline L-Moist & $5.7(7.4,4.0)$ & $6.5(3.8,9.1)$ & $13.4(12.8,14.0)$ & $12.2(15.4,9.0)$ & $4.1(3.2,4.9)$ & $1.4(1.0,1.8)$ \\
\hline L-Seasonal & $23.9(30.0,17.8)$ & $19.8(14.5,25.0)$ & $24.8(21.1,28.5)$ & $18.4(18.8,18.0)$ & $6.7(8.9,4.4)$ & $0.6(0.8,0.4)$ \\
\hline L-Dry & $1.1(1.2,1.0)$ & $2.9(2.2,3.6)$ & $6.1(7.1,5.0)$ & $1.6(2.1,1.0)$ & $0.1(0.0,0.2)$ & $0.1(0.1,0.0)$ \\
\hline M-Moist & $10.0(10.8,9.2)$ & $5.9(4.0,7.7)$ & $3.5(5.1,1.9)$ & $1.7(1.3,2.1)$ & $0.7(0.3,1.1)$ & $0.2(0.0,0.3)$ \\
\hline M-Seasonal & $1.8(0.6,2.9)$ & $2.4(2.7,2.1)$ & $2.1(3.0,1.1)$ & $1.1(1.0,1.2)$ & $0.7(0.1,1.2)$ & $0.0(0.0,0.0)$ \\
\hline Total $^{d}$ & $42.5(50.0,34.9)$ & $37.5(27.2,47.5)$ & $49.9(49,50.5)$ & $35.0(38.6,31.3)$ & $12.3(12.5,11.8)$ & $2.3(1.9,2.5)$ \\
\hline \multicolumn{7}{|l|}{ (c) Vegetation class } \\
\hline Closed forest & $15.9(20.4,11.4)$ & $15.3(11.4,19.1)$ & $23.5(23.8,23.1)$ & $16.6(17.4,15.8)$ & $6.4(6.1,6.6)$ & $1.3(0.5,2.1)$ \\
\hline Open forest & $8.3(9.6,6.9)$ & $9.7(7.9,11.4)$ & $12.1(12.5,11.7)$ & $6.6(7.8,5.3)$ & $1.7(1.9,1.4)$ & $0.4(0.4,0.4)$ \\
\hline Secondary forest & $1.3(1.9,0.6)$ & $1.2(0.7,1.6)$ & $0.7(0.3,1.1)$ & $0.4(0.6,0.1)$ & $0.1(0.1,0.1)$ & $0.0(0.0,0.0)$ \\
\hline Shifting cultivation & $14.3(15.5,13.1)$ & $7.2(4.8,9.6)$ & $6.8(6.7,6.8)$ & $5.4(6.2,4.5)$ & $1.8(2.6,1.0)$ & $0.1(0.0,0.2$ \\
\hline Forest mosaics & $0.7(0.5,0.9)$ & $1.1(0.9,1.2)$ & $2.2\{1.9,2.5\}$ & $2.2(2.8,1.6)$ & $1.2(1.3,1.0)$ & $0.1(0.1,0.1)$ \\
\hline Shrubland & $0.6(1.1,0.1)$ & $0.6(0.9,0.2)$ & $0.9(1.7,0.1)$ & $0.9(1.6,0.1)$ & $0.2(0.3,0.1)$ & $0.0(0.0,0.0)$ \\
\hline Total $^{\text {¿ }}$ & $41.1(49,33)$ & $35.1(26.6,43.1)$ & $46.2(46.9,45.3)$ & $32.1(36.4,27.4)$ & $11.4(12.3,10.2)$ & $1.9(1.0 .2 .8)$ \\
\hline
\end{tabular}

enhancement but is not actually available because of social and economic constraints.

Land availability is also affected by political constraints. Overall, only about one-third of all technically suitable lands in the tropics might be actually available for increasing woody biomass to mitigate global climate change, according to a recent estimate (Trexler 1991). Work in the second phase of this project, not reported here, will therefore integrate the physical resource appraisal described here with the modelling of human systems (Grainger 1993b) to make improved estimates of the area of land in tropical Asia which is actually available for carbon enhancement.

The work described here is an example of the new directions in biogeographical research which the requirements of global climate change mitigation programs have inspired. The potential of satellite imagery is at last being realized to map actual large-area forest distribution. Not only that, but as the needs of policy makers implicitly require determination of the extent to which forest biomass has been degraded by human impact, new methodologies are having to be developed not only to combine physical resource appraisal with the modelling of human systems but to fully integrate these in a spatial context using GIS techniques. This is opening up a huge new window of opportunity for monitoring and modelling large-area real-world vegetation change, with numerous scientific and policy applications.

The policy implications of our study are that GIS/ remote sensing tools will be useful in optimizing the siting of carbon sequestration projects and that international agencies and individual countries should be supported in obtaining state-of-the-art tools as well as the data and personnel appropriate to the task. In addition, donor and recipient countries should be developing and reviewing policy questions and socioeconomic impacts as they head toward implementation of such programs. Because carbon sequestration projects hold promise for reducing the buildup of atmospheric carbon and offer other benefits as well - such as providing wildlife habitat, soil protection, and biodiversity enhancement and protection - pilot projects should be undertaken as soon as possible. Experience with the pilot projects could then be used as a basis for establishing large-scale programs. 
Acknowledgements. This research was sponsored by a cooperative agreement with the U.S. Environmental Protection Agency and the U.S. Forest Service Pacific Northwest Experiment Station (Cooperative agreement No. PNW 910115) to the University of Illinois ( $\mathrm{S}$. Brown and L. Iverson, coprincipal investigators). Thanks also to the people and organizations providing digital data for this project, including K. Singh, M. Lorenzini, and E. Ataman of the United Nations Food and Agricultural Organization in Rome, R. Witt and $O$. Hebin of the United Nations Environmental Program in Geneva, and R. Lozar of the U.S. Army Construction Engineering Research Laboratory in Champaign, Illinois. Thanks also to John Ballenot for reviewing an earlier draft of the manuscript.

\section{LITERATURE CITED}

Box, E. O., Holben, B. N., Kalb, V. (1989). Accuracy of the AVHRR vegetation index as a predictor of biomass, primary productivity and net $\mathrm{CO}_{2}$ flux. Vegetatio 80: $71-89$

Brown, S., Gillespie, A. J. R., Lugo, A. E. (1989). Biomass estimation methods for tropical forests with applications to forest inventory data. For. Sci. 35: 881-902

Brown, S., Iverson, L. R. (1992). Biomass estimates for tropical forests. World Resource Review 4: 366-384

Brown, S., Lugo, A. E. (1982). The storage and production of organic matter in tropical forests and their role in the global carbon cycle. Biotropica 14: 161-167

Brown, S., Lugo, A. E., Iverson, L. R. (1992). Processes and lands for sequestering carbon in the tropical forest landscape. Wat. Air Soil Pollut. 64: 139-155

Brown, S., Lugo, A. E. (1992). Aboveground biomass estimates for tropical moist forests of the Brazilian Amazon. Interciencia 17: 8-18

Brown, S Iverson, L. R., Lugo. A. E. (1993). Land use and biomass changes in Peninsular Malaysia during 1972-82: a GIS approach. In: Dale, V. H. (ed.) Effects of land use change on atmospheric carbon dioxide concentrations: Southeast Asia as a case study. Springer-Verlag, New York (in press)

Collins, M., Sayer, J. A., Whitmore, T C. (eds.) (1991). The conservation atlas of tropical forests: Asia and the Pacific. International Union of Conservation of Nature. Simon and Schuster, New York

Emanuel, W. R., Shugart, H. H., Stevenson, M. P. (1985). Climatic change and the broad-scale distribution of terrestrial ecosystem complexes. Clim. Change 7: 29-43

Flint, E. P., Richards, J. F. (1993). Trends in carbon content of vegetation in south and southeast Asia associated with changes in land use. In: Dale, V. H. (ed.) Effects of land use change on atmospheric carbon dioxide concentrations: Southeast Asia as a case study. Springer-Verlag, New York (in press)

FAO (Food and Agriculture Organization) (1981). Tropical forest resources assessment project. Forest resources of tropical Asia. UN32/6.1301-78-04, Technical Report 3. FAO, Rome

FAO (Food and Agriculture Organization) (1989). Classification and mapping of vegetation types in tropical Asia. FAO, Rome

Goward, S. N., Tucker, C. J., Dye, D. G. (1985). North American vegetation patterns observed with the NOAA-7 advanced very high resolution radiometer. Vegetatio 64 : $3-14$
Grainger, A. (1988). Estimating areas of degraded tropical lands requiring replenishment of forest cover Int. Tree Crops J. 5: 31-61

Grainger, A. (1990a). Modelling the impact of alternative afforestation strategies to reduce carbon dioxide emissions. In: Proceedings of the Intergovernmental Panel on Climate Change, Conference on Tropical Forestry Response Options to Global Climate Change, Sao Paulo, Brazil. Report No. 20P-2003, Office of Policy Analysis, U.S. Environmental Protection Agency, Washington, DC, p. $95-104$

Grainger, A. (1990b). Modelling future carbon emissions from deforestation in the humid tropics. In: Proceedings of the Intergovernmental Panel on Climate Change, Conference on Tropical Forestry Response Options to Global Climate Change, São Paulo, Brazil. Report No. 20P-2003, Office of Policy Analysis, U.S. Environmental Protection Agency, Washington, DC, p. 105-119

Grainger, A. (1991). Constraints on increasing tropical forest area to combat global climate change. In: Howlett, D. Sargent, C. (eds.) Technical workshop to explore options for global forestry management. International Institute of Environment and Development, London, p. 196-208

Grainger, A. (1993a). Controlling tropical deforestation. Earthscan Publications, London

Grainger, A. (1993b). Population as concept and parameter in the modelling of tropical land use change. In: Proceedings of the International Symposium on PopulationEnvironment Dynamics, University of Michigan, Ann Arbor, Michigan (in press)

Holdridge, L. (1967). Life zone ecology. Tropical Science Center, San Jose, Costa Rica

Holben, B. N. (1986). Characteristics of maximum-value composite images of temporal AVHRR data. Int. J. Remote Sensing 7: 1417-1434

Iverson, L. R., Brown, S., Prasad, A., Mitasova, H., Gillespie, A. J. R., Lugo, A. E. (1993). Use of GIS for estimating potential and actual forest biomass for continental South and Southeast Asia. In: Dale, V. H. (ed.) Effects of land use change on atmospheric carbon dioxide concentrations: Southeast Asia as a case study. Springer-Verlag. New York (in press)

Kurz, W. A., Apps, M. J., Webb, T. M., McNamee, P. J. (1992). The carbon budget of the Canadian forest sector: phase I. Information Report NOR-X-326. Forestry Canada, Edmonton, $93 \mathrm{pp}$.

Mitas, L., Mitasova, H. (1988). General variational approach to the interpolation problem. Comput. Math. A.ppl. 16: 983-992

Neilson, R. P., King, G. A., Koerper, G. (1992). Towards a rulebased biome model. Landscape Ecol. 7: 27-43

Prentice, I. C., Cramer, W., Harrison, S. P., Leemans, R., Monserud, R. A., Soloman, A. M. (1992). A global biome model based on plant physiology and dominance, soil properties and climate. J. Biogeogr. 19: 117-134

Running, S. W., Nemani, R., Hungerford, R. D. (1987). Extrapolation of synoptic meteorological data in mountainous terrain and its use for simulating forest evapotranspiration and photosynthesis. Can. J. For. Res. 17: 472-483

Sedjo, R. A., Solomon, A. M. (1989). Climate and forests. In: Rosenberg, N. J., Easterling, W. E., Crosson, P. R. Darmstadter, J. (eds.) Greenhouse warming: abatement and adaptation. Resources for the Future, Washington, DC, p. $105-119$

Schroeder, P. E. (1992). Carbon storage potential of shortrotation tropical tree plantations. For. Ecol. Mgmt (in press) 
Tarpley, J. D., Schneider, S. R., Money, R. L. (1984). Global vegetation indices from the $\backslash() A A-7$ meteorological satellite. J. Clim. appl. Meteorol. 23: 491-494

Trexler, M. C. (1991). Estimatung tropical biomass futures: a tentative scenario. In: Howlett, D., Sargent, C. (eds.) Technical workshop to explore options for global forestry management. International Institute of Environment and Development, London, p. 311-318

Tucker, C. J., Townshend, J T. G., Goff, T. E. (1985a) African landcover classification using satellite data. Science 227 : $369-375$

Tucker, C. J., Vanpraet, C. L., Sharman, M. J., Ittersum, G. (1985b). Satellite remote sensing of total herbaceous biomass production in the Senegalese Sahel: 1980-1984. Remote Sensing Environ. 17: 233-259
Tucker, C. J., Fung, I. Y., Keeling, C. D., Gammon, R. H (1986). Relationship between atmospheric $\mathrm{CO}_{2}$ variations and a satellite-derived vegetation index. Nature 319 $195-199$

Whitmore, T C. (1984). Tropical rain forests of the Far East, 2nd edn. Oxford Science Publications, Clarendon Press, Oxford

Winjum, J., Dixon, R. K., Schroeder, P. E. (1992). Estimating the global potential of forest and agroforest management practices to sequester carbon. Wat. Air Soil Pollut. 64: $213-227$

Yusof, T S. A. K. (Chairman, The Production Team) (1988). Malaysia agricultural directory and index 88/89. Pantai Maju Sdn, Bhd., Selangor, Malaysia 